\title{
Design Analysis of Floating Eccentric Kinematic Linkage for Variable Displacement Pump Application
}

\author{
Rahul S. Yadav*, Balaji D. Kshirsagar, Kunal M. Nawasagare \\ Department of Mechanical Engineering, JSPM'S RSCOE, SPPU, Pune
}

(Received 12 May 2020, accepted 20 July 2020)

Doi: https://doi.org/10.36224/ijes.130205

\begin{abstract}
A centralized lubrication system is a system that delivers controlled amounts of lubricant to multiple locations on a machine while the machine is operating. The advantages of this new technology are clear although the heart of the automated lubrication system is the pump. The conventional pumps used are of fixed displacement type, thus the volume flow cannot be controlled hence they are not useful for the ALS. The Proposed precision control variable displacement pump is an innovative kinematic link base stroke changing mechanism that is controlled using an floating eccentric mechanism that can precisely vary the stroke of the mechanism and thus the pumping unit volume flow rate can be controlled. Project aims at development of the kinematic linkage for above said purpose. The analysis of the kinematic linkage parts will be done using ANSYS workbench 16.0, whereas the actual model that will be developed will be tested to determine the life cycle performance characteristics of the pump. The pump will be tested for fixed input speed and for multiple control positions.
\end{abstract}

Keywords: Automatic lubrication system (ALS), Kinematic link pump, Precision control, Variable displacement pump

\section{Introduction}

Axial piston pumps with constant pressure and variable flow have extraordinary possibilities for controlling the flow by change of pressure. Owing to pressure feedback, volumetric control of the pump provides a wide application of these pumps in complex hydraulic systems, particularly in aeronautics and space engineering.

The major obstacle in application of the bent axis piston pump is extremely high cost over that of the radial piston pump; it ranges in the range of 5 to 6 times the cost of radial piston pump. Hence there is a need to develop a modification in the radial piston pump design that will offer a variable discharge configuration in addition to the advantages of high efficiency and maximum pressure.

Thus, there is need to develop a variable displacement linkage that will enable to vary the stroke of a single cylinder axial piston pump, thereby offering to vary the discharge of the pump using manual control.

\section{Literature review}

Torque ripple attenuation for an axial piston swash plate type Hydrostatic pump: noise considerations", by Viral Mehta Dr. Noah Manring, [1], this paper discusses about the noise generated by axial piston pumps. Chapter 1 begins with the discussion on motivation to 
reduce the pump noise from current level. Thorough background information is given detailing the understanding of this problem and mechanisms involved with it. Some of the standard and in-test methods to alleviate the problem and work in progress by different research groups are presented subsequently. At the end of this chapter, a theory highlighting a different origin of the problem is proposed that challenges the generally accepted view about the noise problem in axial piston pumps and sets foundation for the analysis described in this paper

"Design of a Variable Displacement Triplex Pump" by Shawn Wilhelm, James D. Van de Ven University of Minnesota [2]. This paper presents that conventional variable displacement hydraulic pumps and motors suffer from poor efficiency at low displacements, primarily due to the friction and leakage associated with hydrodynamic bearings, which do not scale with output power. A variable displacement adjustable linkage pump has been developed which can achieve zero displacement and has a constant top dead center position of the pistons, regardless of displacement.

"Design and Testing of an Adjustable Linkage for a Variable Displacement Pump" by Shawn R. Wilhelm, James D. Van de Ven [3]. This paper presents the synthesis, analysis, and experimental validation of a variable displacement six bar crank-rocker-slider mechanism that uses low friction pin joints instead of planar joints as seen in conventional variable pump/motor architectures.

"Design, construction and working of a variable flow radial piston pump using variable displacement linkages" by Vikrant Rajesh Suryawanshi [4]. The study of this paper deals with discharge pumps. A pump is a device that moves fluids (liquids or gases), or sometimes slurries, by mechanical action. In hydraulic power systems, variable displacement pumps save power, increase the productivity or control the motion of a load precisely, safely and in an economical manner. The displacement varying mechanism and power to weight ratio of variable displacement piston pump makes them most suitable for control of high power levels.

\section{Objectives}

Following are the objectives of this project:

1. Design of stroke adjuster mechanism to give zero to maximum stroke displacement of output link displacement, and point to point control of the displacement using stroke variator controlled by control motor.

2. Design \& analysis of components of the variable stroke mechanism and the output displacement link for pump application using Ansys work bench 16.0

3. Experimental analysis of linkage parts for intended life cycle.

\section{Problem definition}

After a careful study of literature on various system researched earlier it is found that most linkages are controlled manually and are not suitable for automatic control the following problems were found in the earlier designs. Earlier mechanism used a variable speed motor to control the speed of the setup which would change with change in voltage and the output was thus not calibrated or reliable. Manual control of the lever made it impossible to get exact flow rate from the device thus the volumetric efficiency calculated was an 
approximation and not accurate. Every time to change the flow rate we had to stop the pump, remove the pulley and then set the angle of control lever manually.

Thus, concluding that the earlier methods are not suitable for automatic lubrication system there is a need to solve this problem by different mechanism.

\section{Solution to problem}

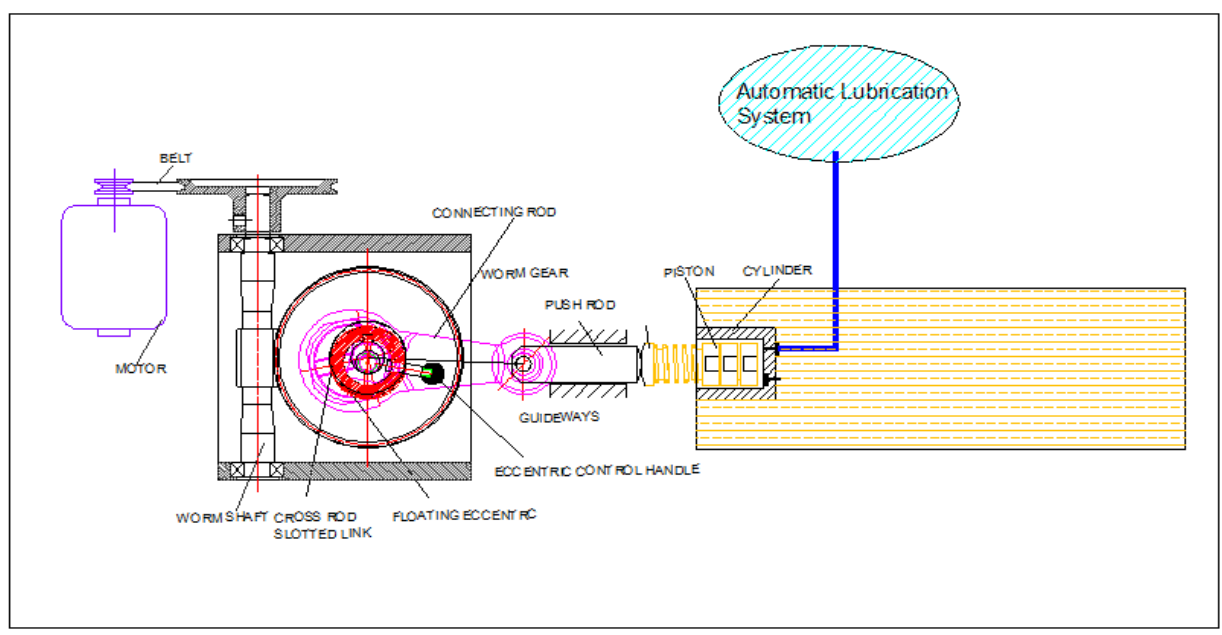

Figure 1: Concept of adjustable stroke mechanism using adjustable pivot drive

The parts of the adjustable stroke mechanism using adjustable pivot drive are shown above.

The main parts are as follows:

1. Input pinion Shaft:

2. Input pinion

3. Input shaft

4. Input Gear

5. Slotted Crank Link

6. Crank

7. Connecting Rod

8. Connecting Link

\section{Construction}

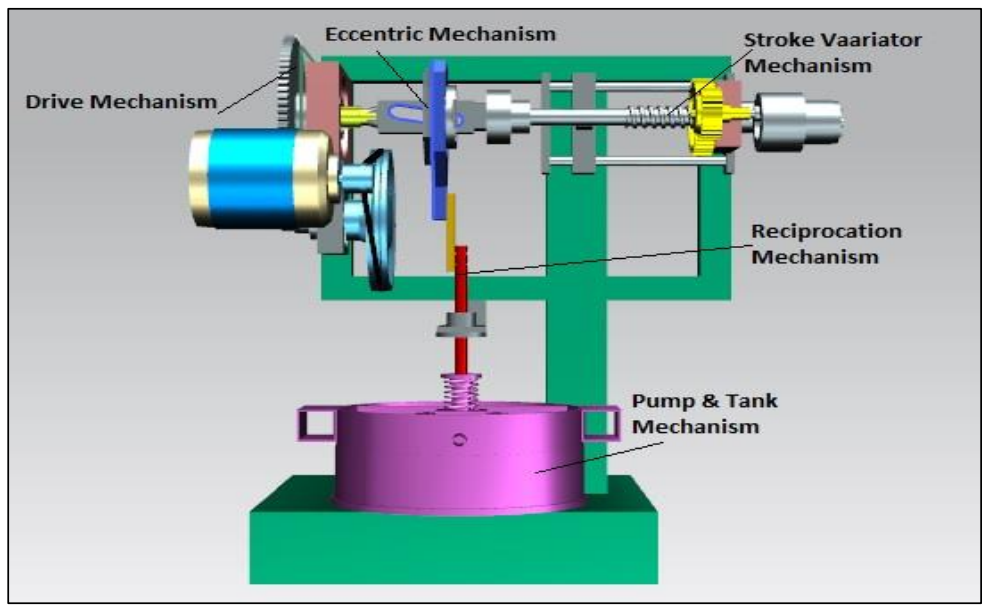

Figure 2: Construction of experimental setup for adjustable stroke mechanism 
This mechanism shown above is to convert rotary motion of crank element into oscillatory output of the output element. The angle of oscillation of the output is a function of the position of eccentric element. The eccentric element position can be varied as it is placed on a slide arrangement coupled to the worm gear box. Thus adjustment of the stroke can be done by varying the position of the pivot element. This mechanism is selected with the view that it offers maximum stability and vibration-less performance owing to nature of mounting of the pivot element which is a sliding pair mounted in a spherical bearing seat giving maximum support to the drive. The slide elements are linear motion bearings that offer friction less sliding motion, thus positioning accuracy can be attained and thus the application motion can be precisely attained.

\section{Working principle of mechanism}

The 12 Volt DC motor is operated using a push button, thus the rotation of motor will rotate the worm which will further rotate the worm gear and thus the coupler shaft will rotate the control screw. The control screw rotation will change the eccentric position of the nut and thereby the floating fulcrum and this will change the oscillation angle of the link-3 and thereby the stroke of cam and thus discharge from pump is changed.

\section{Numerical analysis}

\subsection{Input Pinion Shaft:}

Table 1: Material Selection: -Ref: - PSG (1.10 \& 1.12) + (1.17) [5]

\begin{tabular}{|c|c|c|}
\hline DESIGNATION & ULTIMATE TENSILE STRENGTH & $\begin{array}{c}\text { YEILD STRENGTH } \\
\text { N/mm2 } 2\end{array}$ \\
\hline EN24 & 800 & 680 \\
\hline
\end{tabular}

$\mathrm{fb}$ act $=0.596 \mathrm{~N} / \mathrm{mm} 2$

fs act $<$ fsall Input Pinion shaft is safe under torsional load.

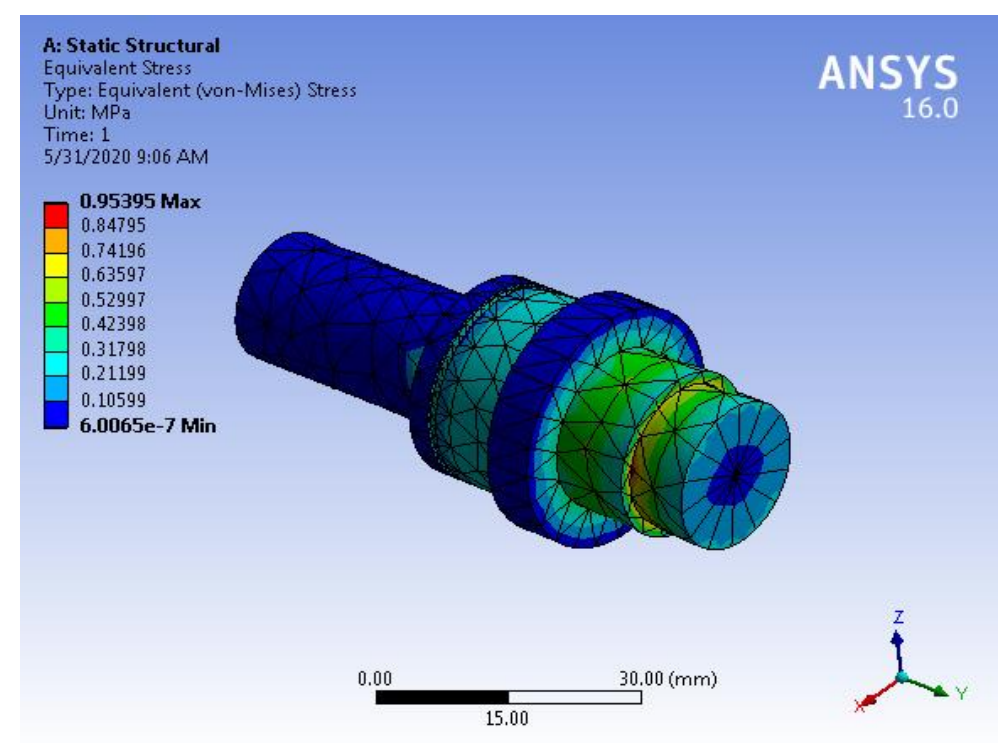

Figure 3: Maximum stress induced in the shaft 
The maximum stress in the part is $0.95 \mathrm{MPa}$ which is far below the allowable value $104 \mathrm{MPa}$ hence the part is safe under given loading conditions

8.2. Design of Crank Link

Table 2: Material Selection: -Ref: - PSG (1.10 \& 1.12) + (1.17) [5]

\begin{tabular}{|c|c|c|}
\hline DESIGNATION & $\begin{array}{c}\text { ULTIMATE TENSILE STRENGTH } \\
\mathrm{N} / \mathrm{mm} 2\end{array}$ & $\begin{array}{c}\text { YEILD STRENGTH } \\
\mathrm{N} / \mathrm{mm} 2\end{array}$ \\
\hline $\mathrm{C} 45$ & 600 & 480 \\
\hline
\end{tabular}

fs all $=81 \mathrm{~N} / \mathrm{mm} 2$

$\mathrm{fb}$ act $=21.51 \mathrm{~N} / \mathrm{mm} 2$

fs act $<$ fs all

Slotted crank link is safe under torsional load.

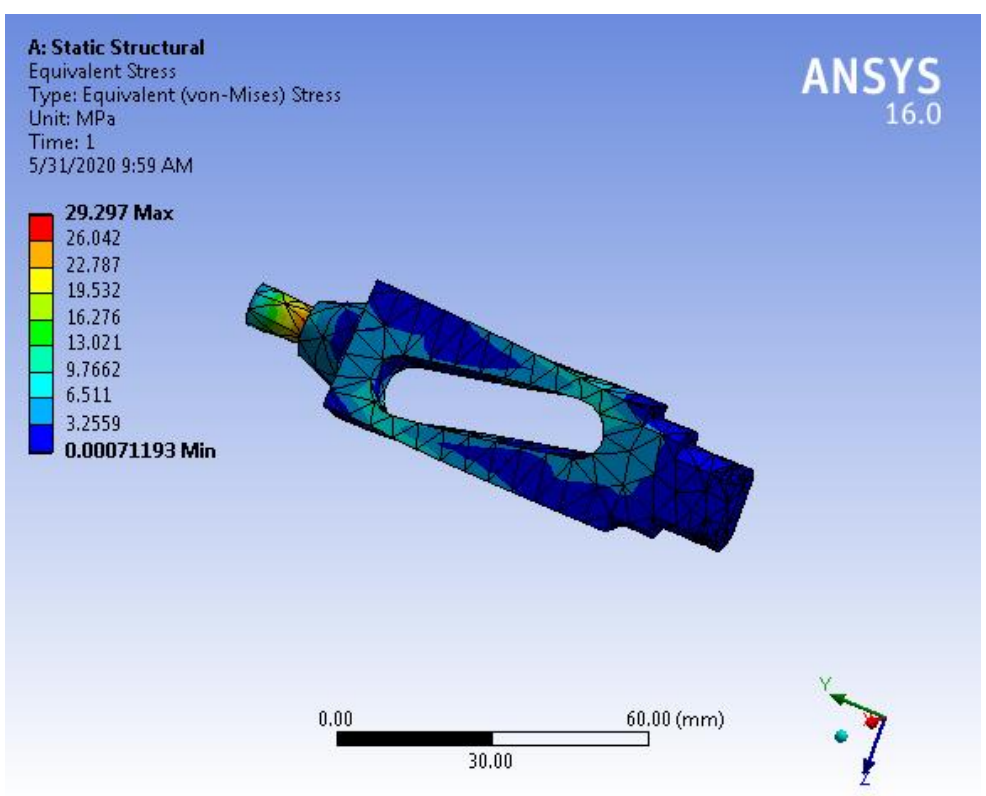

Figure 4: Maximum stress induced in the crank link

The maximum stress in the part is $29.27 \mathrm{MPa}$ which is far below the allowable value $81 \mathrm{MPa}$ hence the part is safe under given loading conditions.

\section{Experimental analysis}

Testing of linkage by actual coupling to the pump:

9.1. Objectives of testing:

a) To determine the functional life of linkage parts under actual linkage loading with pump

b) To check for pump performance and any failures to the linkage parts during given cycle life. 


\subsection{Testing Procedure:}

1. Assemble linkage to the pump \& run with three eccentricities conditions for $60 \mathrm{~K}$ cycles.

2. Check for any failures/ crack propagations in linkage parts after completion of test.

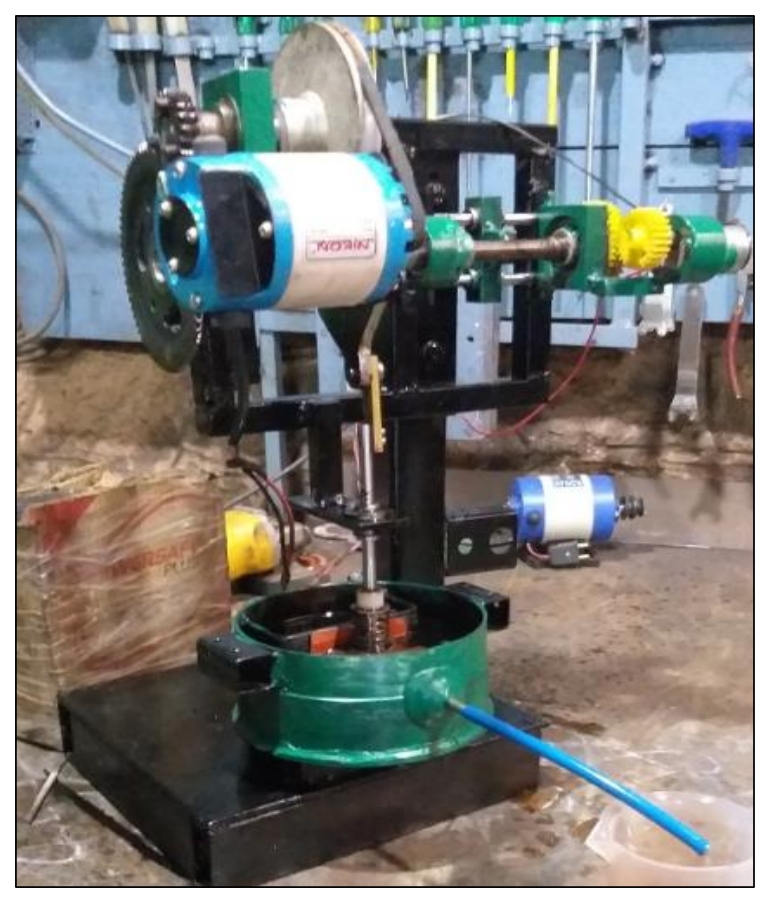

Figure 5: Experimental setup

9.3. Results and discussion

Table 3: Test results

\begin{tabular}{|c|c|c|c|}
\hline $\begin{array}{c}\text { Test } \\
\text { Number }\end{array}$ & $\begin{array}{c}\text { Eccentricity Of Slotted } \\
\text { Crank Link }\end{array}$ & $\begin{array}{c}\text { Number of } \\
\text { Test Cycle } \\
\text { Run }\end{array}$ & Discussion \\
\hline 1 & $\begin{array}{c}\text { 0 eccentricity (No pump } \\
\text { stroke) }\end{array}$ & 60,000 & $\begin{array}{c}\text { Due to zero stroke pump is in idle } \\
\text { condition. No deformation found on } \\
\text { the slotted link \& input shaft pinion } \\
\text { after completion of life cycle test. }\end{array}$ \\
\hline 2 & $\begin{array}{c}3.5 \text { mm eccentricity } \\
\text { (Half pump stroke) }\end{array}$ & 60,000 & $\begin{array}{c}\text { Pump was working fine with half } \\
\text { stroke; flow rate was 145 ml/ Min. No } \\
\text { deformation found on the slotted link } \\
\text { \& input shaft pinion after completion } \\
\text { of life cycle test. }\end{array}$ \\
\hline 3 & $\begin{array}{c}7 \text { mm eccentricity (Full } \\
\text { pump stroke) }\end{array}$ & 60,000 & $\begin{array}{c}\text { Pump was working fine with full } \\
\text { stroke; flow rate was 295 ml/ Min. No } \\
\text { deformation found on the slotted link } \\
\text { \& input shaft pinion after completion } \\
\text { of life cycle test. }\end{array}$ \\
\hline
\end{tabular}




\section{Conclusion}

Test setup had been run for 60k cycles with $20 \mathrm{~W} 40$ oil as flow medium \& with three eccentricity conditions of the linkage. There were no any failures found on the slotted link \& input shaft pinion after completion of life cycle test. Linkage successfully completed the projected life of $60 \mathrm{~K}$ cycle. Further testing can be employed to check other various pump parameters.

\section{References}

[1] Viral Mehta Dr. Noah Manring, Dissertation Supervisor, "Torque ripple attenuation for an axial piston swash plate type Hydrostatic pump: noise considerations", A Dissertation presented to the faculty of the Graduate School University of Missouri - Columbia

[2] Shawn Wilhelm, James D. Van de Ven, "Design of a Variable Displacement Triplex Pump" University of Minnesota, conference paper, ConfPaper-IFPE2014

[3] Shawn R. Wilhelm, James D. Van de Ven. "Design and Testing of an Adjustable Linkage for a Variable Displacement Pump" Article in Journal of Mechanisms and Robotics 5(4):041008 - November 2013

[4] Vikrant Rajesh Suryawanshi. "Design, construction and working of a variable flow radial piston pump using variable displacement linkages" International Research Journal of Engineering and Technology (IRJET) Volume: 02 Issue: 07 | Oct-2015

[5] PSG design data handbook.

[6] Li Cheng Gong \& Zong-xia, "Thermal Hydraulic Modeling And Simulation Of Piston Pump", School of Automatic Science and Electrical Engineering, Beijing University of Aeronautics and Astronautics, Beijing, Vol.19 No.4

[7] Galal Ali Hassaan, Emeritus Professor, Faculty of Engineering, Cairo University, Egypt, "Synthesis of Planar Mechanisms; Part IV: Four-bar Mechanism for Four Coupler Positions Generation” International Journal for Research in Applied Science \& Engineering Technology (IJRASET), Volume 3 Issue V, May 2015

[8] Neelam M. Kamthe, Manmohan M. Bhoomkar, Ganesh E. Kondhalkar, Department of Mechanical Engineering, Pune University / ABMSP's APCOER, Pune, India. “Design, Development and Analysis of Variable Displacement Pump by Application of Linkage Motion Adjuster" International Journal of Engineering Trends and Technology (IJETT) - Volume 32 Number 3- February 2016

[9] C. M. Veerendra kumar, V. B. Math, Department of Automobile Engineering, Research Scholar, Basaveshwar Engineering College, Bagalkot -587102, Karnataka, India "Kinematic Synthesis Of Planar Adjustable Six Bar Mechanism For Specified Output" International Journal of Research in Engineering and Technology, Volume: 05 Special Issue: 13

[10] Daniel g. Olson, Arthur g. Erdman and Donald r. Riley Productivity Centre, University of Minnesota, "A Systematic Procedure For Type Synthesis Of Mechanisms With Literature Review”, Mechanism and Machine Theory Vol. 20, No. 4. pp. 285-295, 1985 